\title{
The Role That Cognition Plays in Attitude Formation: An Alternative Model for the Determinants of Attitude
}

\author{
Dr. Chih-Hsuan Huang \\ Dept. of Business Administration, Tunghai University \\ No.1727, Sec.4, Taiwan Boulevard, Xitun District, Taichung 407, Taiwan \\ Tel: 886-4-23590121 ext. 30175 E-mail: tititacer@thu.edu.tw
}

Dr. Amanda Beatson

Business School, Queensland University of Technology

2 George St, Brisbane, QLD 4000, Australia

Tel: 61-7-3138-1241Ｅ-mail: a.beatson@qut.edu.au

Professor Ian Lings (Corresponding author)

Business School, Queensland University of Technology

2 George St, Brisbane, QLD 4000, Australia

Tel: 61-7-3138-2972Ｅ-mail: ian.lings@qut.edu.au

Received: April 4, $2015 \quad$ Accepted: April 15, $2015 \quad$ Published: April 15, 2015

doi:10.5296/jmr.v7i3.7376 URL: http://dx.doi.org/10.5296/jmr.v7i3.7376

\begin{abstract}
Despite the literature supporting the role of attitude in exploring consumer behavior, we still know very little about the cognitive factors that directly or indirectly influence attitude. Through a series of three studies, the relationships between cognitive factors and attitude were explored. This research showed that attitude is directly influenced by concern. In addition, our research demonstrates the potential impact of moderators between concern and attitude. Consumption influenced by high perceived value for money and high outcome expectancy was linked to higher levels of concern and contributed to higher attitude. Finally, the theoretical and practical implications of these findings were discussed.
\end{abstract}

Keywords: Cognition, Attitude, Concern, Outcome expectancy, Perceived value for money, 
Environmentally-friendly products, Confirmatory factor analysis, Hierarchical moderated regression analysis 


\section{Introduction}

For many years, consumer behavior research has explored the reasons behind changes in behavioral patterns. Research into behavioral domains has revealed the direct impact of cognition on behavior. However, several researchers demonstrate disappointing correlations between cognition and behavior (see for example, Oslamp et al., 1991; Bamberg, 2003). Instead, the importance of cognition as determinants of attitude has been emphasized; for example, specific beliefs impact directly on attitudes, which in turn form behavioral intention or behavior (Ajzen and Fishbein, 1980; Ajzen, 1991).

Although attitude research has emphasized the cognitive factors (e.g., beliefs) that are determinants of attitude (Ajzen and Fishbein 1980; Ajzen, 1991; Eagly et al., 1994; Ajzen, 2005), several researchers demonstrate that other factors impact upon attitude. Bodur et al. (2000) point out that affect has a direct effect on attitude, as well as an indirect effect that is mediated by the individual's belief. In addition, Bamberg (2003) indicates that when individuals are concerned about a specific issue, the attitudes they hold about that issue are more likely to be strong. These previous studies demonstrate a number of factors that predict attitude. They indicate that the relevant factors that explain the determinants of attitude are still ambiguous.

The current research is designed to contribute insights into a series of cognitive determinants of attitude. Cognitions reflect a group of mental processes that go on in the mind (Hollnagel, 2002), which is used in the field of social psychology to explain attitudes, attribution, and group dynamics (Feldman, 1981; Alhabeeb, 2006; Scherr and Hammer, 2009). If such cognitive determinants of attitude can be identified, it enables researchers to better understand the formation of attitude and, in turn, could motivate consumers' behavioral intention or behavior (Ajzen, 1991). To achieve this, further systemic, rigorous investigation of the potential cognitive factors on attitude is required.

A conceptual model was developed in this research in order to provide a more comprehensive understanding of the determinants of consumer attitudes. The following sections will develop the conceptual framework along with the research hypotheses, test it empirically, and discuss the implications of the findings.

\section{Conceptual model and hypotheses}

Attitude research has emphasized the importance of understanding the relationship between cognition and attitude (Eagly et al., 1994; Bodur et al., 2000). Cognition reflects a group of information processes that occur in our mind (Hollnagel, 2002), which directly or indirectly impact on attitude. Yet, potentially, there are other cognitive factors that influence attitude that also exist and require identification. We postulate a series of cognitive factors that contribute to a better understanding of the determinants of attitude. The impacts of these cognitive factors on attitude are discussed as follows.

\subsection{Concern}

Concern is regarded as an essential cognitive factor that influences attitude. Concern is something that relates to, or influences, a person's cognitive structure (Williams, 2008). In 
reviewing research on concern, several studies argue that concern involves values, an attitude toward facts, or a cognitive evaluation of one's own behavior (Fransson and Gärling, 1999; Bamberg, 2003; Schultz, 2001). It seems, then, that concern may refer to attitude. Further, studies have indicated that a link exists between concern and attitude. Black et al. (1985) and Bamberg (2003) suggest that concern leads to attitude. They concluded that the degree of concern for an issue is a direct predictor of the specific attitude toward a given behavior regarding the issue. This position is consistent with the correspondence principle suggested by Ajzen and Fishbein (1977), which assumes that a substantial relationship between attitude and behavior is demonstrated only when the attitudinal and behavioral measures correspond to each other, with respect to time frame, target, action and context. Consequently, we postulate that consumers would hold more positive specific attitudes about a given behavior in response to an issue if they are more concerned about the issue. The first hypothesis is therefore proposed:

$\mathrm{H}_{1}$. Concern has a positive association with attitude.

Further, we argue that concern leads to attitude, but only when a successful behavior al outcome and high perceived value for money is expected. Outcome expectancy and perceived value for money have been suggested as cognitive factors that significantly influence human behavior; however, the roles that these two factors play in attitude formation are still ambiguous.

\subsection{Outcome expectancy}

According to Bandura's Social Cognitive Theory, outcome expectancy is a helpful cognitive factor that impacts significantly on human behavior (Bandura, 1986). It is conceptualized as the belief that performing a given behavior will or will not result in specific consequences (Bandura, 1986). A review of marketing and psychology literature supports the role of outcome expectancy in a range of disciplines. For example, cross-sectional studies on exercise psychology show that people who exercise more report higher positive outcome expectancy and people who exercise less report lower outcome expectancy (Williams et al., 2005).

Implicitly or explicitly, the notion of outcome expectancy is applied to explain attitude formation. Ajzen (1991) takes the perspective that attitudes toward the behavior are determined by a cognitive structure, based on accessible beliefs about the likely consequences of the behavior, termed behavior al beliefs (Ajzen, 1991; Ajzen and Fishbein, 1980). Although a direct causal impact of outcome expectancy on attitude has been emphasized, very little is known about the moderating roles that outcome expectancy play in attitude formation. As suggested by Dabholkar and Bagozzi (2002), the moderating effects are more meaningful in some instances than the direct effects. Kushner et al. (1994), for example, found that outcome expectations strengthen the relationship between anxiety level and alcohol consumption. This research suggests that those with high tension-reduction alcohol outcome expectations showed a stronger positive correlation between anxiety and drinking behavior than those with low tension-reduction alcohol outcome expectations. We argue that if people believe that their actions (e.g., go jogging three times a week) will result 
in specific positive consequences (e.g., good health), this belief should positively affect their attitudes toward those actions. More specifically, consumers are more likely to be concerned about an issue and form a positive attitude toward a given behavior directed at resolving the issue if they believe that positive outcomes will result from performing the behavior. That is, the relationship between concern and attitude is proposed to be moderated by outcome expectancy. Consequently, it is posited that:

$\mathrm{H}_{2}$. The influence of concern on attitude is stronger if consumers have a high level of outcome expectancy.

\subsection{Perceived value for money}

Previous studies have suggested that perceived value for money is a significant cognitive factor that drives behavioral decisions and influences an individual's action (Foley \& Pollard, 1998; Little, 2010). Perceived value for money represents consumers' perceptions of what is obtained and what is given for each purchase (Caruana et al., 2000). This process emphasizes an overall assessment of the utility of a product/service, as perceived by consumers in terms of benefits and costs. Consequently, high perceived value for money should be perceived when something delivers greater benefits than costs.

A review of the literature provides support for a significant direct link between perceived value for money and attitude (Swait and Sweeney, 2000; Collins-Dodd and Lindley, 2003; Turel et al., 2007). For example, in the context of brand perception, perceived value for money of store brands has been shown to influence attitudes toward store brands (Richardson et al., 1996; Collins-Dodd and Lindley, 2003). While the direct association between perceived value for money and attitude has been examined, the moderating effect of perceived value for money has received relatively little attention in attitude formation. We argue that if people perceived that high value for money is derived from performing their actions, this should contribute positively to their attitudes toward those actions. Specifically, consumers are more likely to be concerned about an issue and develop a favorable attitude toward a given behavior directed at resolving the issue if they perceive high value is likely to be derived from the behavior. Perceived value for money is therefore proposed to moderate the relationship between concern and attitude. Consequently, we propose that:

$\mathrm{H}_{3}$. The influence of concern on attitude is stronger if consumers perceive a high level of value for money.

Based on the discussions above, the relationships between several essential cognitive factors believed to influence attitude are focused upon in this research. Our conceptual model is depicted by the paths linking hypothesized relationships between variables (see Figure 1). 


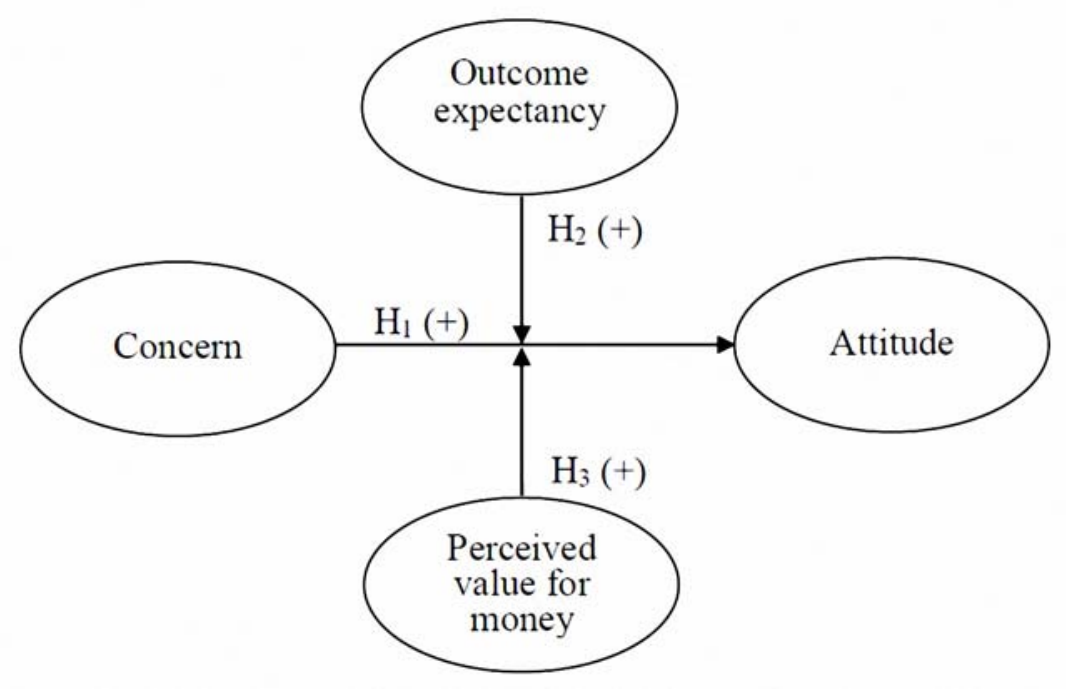

Figure 1. Conceptual Model

\section{Method}

\subsection{Empirical context}

In order to pursue sustainable development and management, the role of the environment in consumer behavior has become an important research topic for both researchers and marketers (Panayotou, 1993; Peattie and Crane, 2005; Rex and Baumann, 2007; Van Dam \& Apeldoorn, 1996). Despite the literature supporting the role of attitude in exploring behavioral intention or behavior, behavioral inconsistency that constrains consumers from taking further action on environmental behaviors still exists (AccountAbility, 2008). To better understand the determinants of consumers' attitudes in the context of environmental behaviors, three studies (i.e., public transport, organic vegetables and free-range eggs) related to consuming environmentally-friendly products were examined.

These three studies were chosen as useful examples with which to test our conceptual model for three reasons. First, everyone is capable of enacting these behaviors in daily life because they have a lower monetary cost than other environmentally-friendly behaviors, such as installing appliances that run on solar energy. Second, these three specific studies represent monetary outlays rather than savings. Thus, a judgment of perceived value for money can be made as an assessment of the costs and benefits when consumers make a purchase. Third, these three specific studies were identified in pre-test interviews as essential environmental behaviors.

\subsection{Procedure and data collection}

Data were collected using an online survey. A non-probability sampling technique of quota sampling via volunteer opt-in panels was used to recruit consumers in Australia (Sue and Ritter, 2007). Volunteer opt-in panels are considered as appropriate approaches for conducting representative surveys when the results are interfered to a larger population (Crabtree, 2000; James, 2000; McDevitt and Small, 2002). Specifically, the quotas of 
respondents for geographical distribution were roughly matched accordingly to the ratio of the national representative figures of the Australian Bureau of Statistics (ABS) in 2011(ABS, 2011). The screening for the quotas requested for geographical distribution should minimize the effects of a skewed internet population (Evans and Mathur, 2005). Respondents were randomly selected from a panel of willing participants previously recruited from the general public (Göritz, 2004). They were contacted by e-mail and asked to participate in the survey. Each study consisted of 250 respondents, totally 750 respondents across all three studies. Respondents are in a range of 25 to 45 years, with a roughly equal gender distribution.

\subsection{Measures}

Items from prior research were used as the basis of measures for the constructs. A protocol analysis and a pre-test were also used to improve measures and fit the context being investigated (Zikmund and Babin, 2007). A full list of items for each construct is provided in Appendix I. With the exception of the measure of attitude, the seven-point Likert scale anchored by 1 (strongly disagree) and 7 (strongly agree) were used throughout. The process of creating and validating each scale is now described.

Concern. We termed concern as based on environmentally related issues. Concern was operationalized as environmental concern and was defined as consumers being concerned about threats to the environment. The six items used to measure environmental concern were drawn from Kilbourne and Pickett's (2008) environmental scale.

Outcome expectancy. We operationalized outcome expectancy as the belief that performing the three specific environmental behaviors resulted in positive consequences. The six items were drawn from Kilbourne and Pickett's (2008) environmental scale to measure consumers' belief in the existence of environmental problems, which could be mitigated by performing a specific environmental behavior.

Perceived value for money. Perceived value for money is operationalized as an overall assessment of the utility of consumption of a specific environmental behavior perceived by consumers in terms of what is received (e.g., benefits) and what is given (e.g. costs). We drew the single item measuring perceived value for money from the recommendations of Caruana et al. (2000).

Attitude. Attitude is operationalized as consumers' overall evaluations of performing a specific environmental consumption behavior. Respondents were asked to report their attitudes toward performing the behavior on three 7-point semantic differentials items: bad/good, unpleasant/pleasant, and worthless/valuable. These adjective pairs were drawn from Ajzen's (2002) scale and have been widely used as reliable indicators of attitude in a range of behavioral domains (e.g., Bodur et al., 2000).

\section{Results}

\subsection{Data validation}

To assess the data for the three studies, all measures were first subjected to factor analysis (FA) using SPSS 19.0. Principal components factor analysis and oblique rotation was 
conducted to refine the scales. Subsequently, confirmatory factor analysis (CFA) used AMOS 18.0. Structural equation modeling was used to verify and validate the scales. For each scale, FA results show that items exhibited statistically significant loadings on their expected factors, with high item-to-total correlations. In each study, CFA results indicate that the measurement model produces satisfactory goodness-of-fit statistics (Hu and Bentler, 1999). Cronbach's (1951) alpha coefficient, composite reliability, and average variance extracted (AVE) are presented in Table 1. Cronbach's alpha coefficient indicates that the scales exhibit adequate internal consistence, with all alpha values above 0.70 (Nunnally, 1978). CFA results reveal that the composite reliability of the scales exceeds the recommended 0.70 threshold and that the AVE values were above 0.50, providing evidence of convergent validity (Bagozzi and Yi, 1988). The discriminant validity was assessed following the recommendation of Bagozzi and Phillips (1982). All pairs of constructs were tested using a chi-square difference and the results present their distinctiveness, in support of discriminant validity.

Table 1. Measurement model results

\begin{tabular}{|c|c|c|c|}
\hline \multirow[b]{2}{*}{ Research constructs } & \multicolumn{3}{|c|}{ PT/OV/FRE } \\
\hline & Cronbach's alpha & $\begin{array}{l}\text { Composite } \\
\text { reliability }\end{array}$ & $\begin{array}{l}\text { Average variance } \\
\text { extracted }\end{array}$ \\
\hline $\begin{array}{l}\text { Environmental } \\
\text { concern }\end{array}$ & $0.94 / 0.95 / 0.96$ & $0.87 / 0.88 / 0.90$ & $0.52 / 0.54 / 0.60$ \\
\hline Outcome expectancy & $0.95 / 0.94 / 0.97$ & $0.87 / 0.86 / 0.92$ & $0.52 / 0.51 / 0.66$ \\
\hline Attitude & $0.86 / 0.88 / 0.90$ & $0.72 / 0.75 / 0.81$ & $0.50 / 0.51 / 0.59$ \\
\hline Fit statistics & $\begin{array}{l}\chi^{2} \text {-value of } 252.51 \\
(d f=37, p=0.00) \\
\text { GFI }=0.90 \\
\text { CFI }=0.96 \\
\text { RMSEA }=0.07\end{array}$ & $\begin{array}{l}\chi^{2} \text {-value of } 363.99 \\
(d f=37, p=0.00) \\
\text { GFI }=0.90 \\
\text { CFI }=0.93 \\
\text { RMSEA }=0.08\end{array}$ & $\begin{array}{l}\chi^{2} \text {-value of } 333.40 \\
(d f=37, p=0.00) \\
\text { GFI }=0.91 \\
\text { CFI }=0.95 \\
\text { RMSEA }=0.07\end{array}$ \\
\hline
\end{tabular}

\subsection{Method biases}

One partial explanation for the relationships between all constructs in the conceptual model may be the existence of systematic measurement error. Such systematic error commonly arises from self-report bias and takes the form of social desirability bias (Lings and Greenley, 2005). Social desirability arises as a result of the consumers' tendency to present themselves in a favorable way, regardless of their true feelings (Paulhus, 1991; Podskoff et al., 2003). Social desirability was measured using Strahan and Gerbasi's (1972) short form of the Marloew-Ceowne Social Desirability Scale (Crowne and Marlowe, 1960). Examining the correlations of the social desirability measure with all of the items used in this research revealed that social desirability bias was not an issue in these data. Additionally, a further post hoc test for common method bias, a Harman's (1967) one-factor test, was performed following the approach described by Podsakoff et al. (2003). Results indicated that common method bias does not represent a significant concern.

\subsection{Model testing}

To assess the robustness of our conceptual model, the application of Study 1 (public transport) 
was examined first. A hierarchical moderated regression was used to test our hypotheses (Cohen and Cohen, 1983). All scales were averaged to form a composite. Once the composites were formed we mean-centered the constructs to avoid any potential threat of multicollinearity when calculating interaction terms (Aiken and West, 1991). The results of the hierarchical moderated regression analysis are reported in Table 2.

In Step $1\left(\mathrm{R}^{2}=8.40 \%\right)$, the main effect of environmental concern on attitude was entered. In Step $2\left(\mathrm{R}^{2}=27.10 \%\right)$, environmental concern was entered along with outcome expectancy and perceived value for money. Finally, Step $3\left(\mathrm{R}^{2}=30.30 \%\right)$ included environmental concern, outcome expectancy, perceived value for money, and two-way interactions.

The findings show that the effect of environmental concern on attitudes toward consumption decisions relating to public transport was significant $(\beta=0.29, p<0.01)$ in Step 1. Therefore, $\mathrm{H}_{1}$ was supported. The next set of hypotheses $\left(\mathrm{H}_{2}\right.$ and $\left.\mathrm{H}_{3}\right)$ examines the moderating effects as judged by the two-way interactions in Step 3. In examining the moderating effect of outcome expectancy, the results indicate that outcome expectancy $(\beta=-0.06, p=0.39)$ had no significant impacts on the relationship between environmental concern and attitude. The results lead us to reject $\mathrm{H}_{2}$. However, we find that the positive effect of environmental concern on attitude is bolstered when perceived value for money is high $(\beta=0.14, p<0.05)$, thus supporting $\mathrm{H}_{3}$.

Table 2. Hierarchical regression results (public transport)

\begin{tabular}{|c|c|c|c|c|c|c|}
\hline \multirow{2}{*}{$\begin{array}{l}\text { Dependent variable } \\
\text { Attitude }\end{array}$} & \multicolumn{2}{|l|}{ Step 1} & \multicolumn{2}{|l|}{ Step 2} & \multicolumn{2}{|l|}{ Step 3} \\
\hline & $\beta$ & t-value & $\beta$ & t-value & $\beta$ & t-value \\
\hline \multicolumn{7}{|l|}{ Main effect } \\
\hline $\begin{array}{l}\text { Environmental concern } \\
\text { (Hypothesis 1) }\end{array}$ & $0.29 * *$ & 4.77 & 0.06 & 0.96 & 0.08 & 1.21 \\
\hline Outcome expectancy & & & $0.20 * *$ & 2.83 & $0.20^{* *}$ & 2.84 \\
\hline Perceived value for money & & & $0.36^{* *}$ & 5.59 & $0.34 * *$ & 5.24 \\
\hline \multicolumn{7}{|l|}{ Two-way interaction } \\
\hline $\begin{array}{l}\text { Environmental concern* } \\
\text { outcome expectancy } \\
\text { (Hypothesis 2) }\end{array}$ & & & & & -0.06 & -0.87 \\
\hline $\begin{array}{l}\text { Environmental concern* } \\
\text { perceived value for money } \\
\text { (Hypothesis 3) }\end{array}$ & & & & & $0.14^{*}$ & 1.97 \\
\hline$R^{2}$ & \multicolumn{2}{|l|}{0.08} & \multicolumn{2}{|l|}{0.27} & \multicolumn{2}{|l|}{0.30} \\
\hline
\end{tabular}

Note: $\lceil *\rfloor: \mathrm{p}$-value $<0.05 ; \quad\lceil * *\rfloor: p$-value $<0.01$

\subsection{Model validation}

Study 2 (organic vegetables) and Study 3 (free-range eggs) were also conducted to validate our conceptual model, and the same format applied to Study 1 (public transport) was used. The standardized coefficients of parameters for both studies are presented in Table 3. The reliability and discriminant validity of items measuring the constructs in both studies were also achieved. The results for both studies indicate that environmental concern had a positive 
impact on attitude. With regard to the moderating effects, the results show that outcome expectancy had only a positive significant impact on the relationship between environmental concern and attitude in purchase decisions about free-range eggs. Additionally, perceived value for money only emerged as a significant moderator between environmental concern and attitude in purchase decisions about organic vegetables. The summary of the hypotheses results across the three studies is presented in Table 4.

Table 3. Path coefficients for organic vegetables and free-range eggs

\begin{tabular}{|l|l|l|l|l|}
\hline \multirow{2}{*}{ Hypothetical path } & \multicolumn{2}{|c|}{ OV } & \multicolumn{2}{c|}{ FRE } \\
\cline { 2 - 5 } & \multicolumn{1}{|c|}{$\beta$} & t-value & \multicolumn{1}{c|}{$\beta$} & t-value \\
\hline $\mathrm{H}_{1}:$ Environmental concern $\rightarrow$ Attitude & $0.50^{* *}$ & 9.12 & $0.42^{* *}$ & 7.38 \\
\hline $\begin{array}{l}\mathrm{H}_{2}: \text { Environmental concern*outcome } \\
\text { expectancy } \rightarrow \text { Attitude }\end{array}$ & -0.10 & -1.71 & $0.12^{*}$ & 2.02 \\
\hline $\begin{array}{l}\mathrm{H}_{3}: \text { Environmental concern control*perceived } \\
\text { value for money } \rightarrow \text { Attitude }\end{array}$ & $0.19^{* *}$ & 3.32 & -0.09 & -1.10 \\
\hline
\end{tabular}

Note: OV: organic vegetables; FRE: free-range eggs

Table 4. The summary of hypotheses results (all three studies)

\begin{tabular}{|l|c|c|c|c|}
\hline Hypothetical path & Expected & \multicolumn{3}{|c|}{ Context } \\
\cline { 3 - 5 } & sign & PT & OV & FRE \\
\hline $\mathrm{H}_{1}:$ Environmental concern $\rightarrow$ Attitude & + & $\sqrt{ }$ & $\sqrt{ }$ & $\sqrt{ }$ \\
\hline $\begin{array}{l}\mathrm{H}_{2}: \text { Environmental concern*outcome expectancy } \rightarrow \\
\text { Attitude }\end{array}$ & + & $\times$ & $\times$ & $\sqrt{ }$ \\
\hline $\begin{array}{l}\mathrm{H}_{3}: \text { Environmental concern control*perceived value for } \\
\text { money } \rightarrow \text { Attitude }\end{array}$ & + & $\sqrt{ }$ & $\sqrt{ }$ & $\times$ \\
\hline
\end{tabular}

Note: PT: public transport; OV: organic vegetables; FRE: free-range eggs

\section{Discussion}

From a theoretical standpoint, this research offers insights and empirical evidence to better understand consumers' attitudes. Specifically, our research contributes to current theorizing by investigating further cognitive factors that influence attitude. A series of relationships between cognitions and attitude are investigated. The results of all three reported studies, which investigated the consumption of public transport (Study 1), organic vegetables (Study 2) and free-range eggs (Study 3), are consistent with Bamberg's (2003) finding that consumers' attitudes toward a given behavior directed at resolving an issue are influenced by consumers' concerns about resolving the issue.

The potential impact of moderators between concern and attitude was tested. Outcome expectancy and perceived value for money were found to be essential moderators influencing attitude. In fact, the moderating effects of these cognitive factors are more meaningful in some instances than the direct effects (Dabholkar and Bagozzi, 2002). The consumption of free-range eggs suggests that concern for an issue (e.g., concern for the environment) and 
attitudes toward a given behavior directed at resolving the issue (e.g., consuming free-range eggs) are highly correlated for consumers with high expectations of positive outcome from performing the behavior (e.g., environmentally-friendly outcomes for animals). The results of the consumption of public transport and organic vegetables reveal some conflicting evidence regarding the moderating role of outcome expectancy on the relationship between concern and attitude. However, outcome expectancy has been demonstrated across a number of contexts (Waters et al., 2012). The influence of perceived value for money on the relationship between concern and attitude has also been investigated. The importance of perceived value for money emerged in the consumption of public transport and organic vegetables, both of which indicate that concern for an issue (e.g., concern for the environment) and attitudes toward a given behavior directed at resolving the issue (e.g., consumption of public transport and organic vegetables) are strongly correlated for those who perceive that high value for money will be derived from the behavior. In terms of the consumption of free-range eggs, however, perceived value for money did not appear to have an effect. Overall, the results indicate that perceived value for money has a considerable influence on attitudes across a number of contexts.

On a practical note, the identification of cognitive determinants of attitude enables practitioners to encourage the formation of desirable attitudes (e.g., favorable attitudes toward specific environmental behaviors) and improve those attitudes by emphasizing specific cognitive factors. The findings of this research program suggest that a number of key cognitive factors drive consumers' attitudes. Those consumers who are concerned about the environment tend to hold favorable attitudes toward environmental behavior. Practitioners could provide environmental knowledge regarding beneficial and harmful actions that contribute to reducing environmental deterioration, to arouse consumer concerns for the environment.

Further, the findings suggest that consumers who are more concerned about the environment tend to hold more favorable attitudes toward a specific environmental behavior if they expect the behavior will result in a successful outcome. This finding, however, was only identified in the consumption of free-range eggs which may be because consumers tend to observe tangible impacts on the environment. More information about the potentially positive impact that environmental behavior could have on the environment should enhance consumers' expectations that tangible benefits will result from the behavior. For example, taking public transport will improve outdoor air-quality and consuming organic vegetables will reduce the use of chemicals in agriculture.

The impact of perceived value for money on the relationship between environmental concern and attitude was also reported. The findings show that consumers who are more concerned about the environment tend to hold more favorable attitudes toward a specific environmental behavior if they perceive that high value for money will be derived from the behavior. This finding was identified from both the consumption of public transport and organic vegetables. High perceived value for money occurs when consumers perceive that a behavior will result in more benefits than costs. Consequently, more campaigns are suggested to highlight the benefits of consuming free-range eggs (e.g., a healthier choice or more 
environmentally-friendly outcomes for animals), to enhance perceptions of higher value as a result of consumption.

As with most research efforts, the studies reported in this research are not without their limitations. First, the research program is restricted in terms of the potential factors that may be related to, or impact on consumers' concern for an issue. People in different social environments may obtain different information that will form the basis for their concern for an issue. For example, belief may influence the way we recognize things. Kilbourne and Pickett (2008) suggest that beliefs precede concern. Further, environmental concern would not arise unless individuals believe that environmental problems exist (Kilbourne and Pickett, 2008). Hence, potentially relevant factors that further explain the determinants of attitudes still exist. Whether concern is or is not influenced by other factors is worthy of further investigation.

Second, the research is restricted in generalisability. Our conceptual model was tested in an environmental context, but whether this model could be generalized to other contexts requires further empirical investigation.

Finally, this research is limited, in particular, by its population. The respondents of these three studies were Australian consumers. The results of our behavioral model may not generalize to other populations. Previous studies suggest that cultural differences influence the attitudes consumers hold (e.g., Gan et al., 2008; Laroche et al., 2001). For example, Western consumers (e.g., those living in Canada, Australia and New Zealand) reflect a continued, broad increase in environmental consciousness (AccountAbility, 2008; Gan et al., 2008; Laroche et al., 2002). In general, Asian consumers are less likely to express much concern about conserving biodiversity or maintaining the balance of nature for its own sake (Rambo, 2001). The different levels of environmental consciousness in different countries may be responsible for different concern for the environment and attitudes about environmentally-friendly behavior. In the future it would be useful to validate the findings of this research with samples drawn from Asian countries. More insightful conclusions could then be drawn using cross-cultural comparisons.

\section{Acknowledgement}

The research is financed by Business School, Queensland University of Technology.

\section{References}

ABS. (2011). Australian Demographic Statistics. Retrieved from http://www.abs.gov.au/AUSSTATS/abs@.nsf/allprimarymainfeatures/81C5AE743DDCF8F0 CA257A850013DF4C?opendocument

AccountAbility. (2008). What Assures Consumers in Australia on Climate Change? Switching on Citizen Power. from http://www.accountability21.net/uploadedFiles/What $\% 20$ Assures $\% 20$ Consumers $\% 20 \mathrm{in} \% 20$ Australia\%20on\%20Climate\%20Change.pdfm

Aiken, L. S., \& West, S. G. (1991). Multiple regression: Testing and interpreting interactions, 
Newbury Park: SAGE Publication.

Ajzen, I. (1991). The theory of planned behavior. Organizational Behavior and Human Decision Processes, 50, 179-211.

Ajzen, I. (2002). Constructing a TPB questionnaire: Conceptual and methodological considerations. Retrieved from http://people.umass.edu/ aizen/pdf/tpb.measurement.pdf

Ajzen, I. (2005). Attitudes, personality, and behavior, New York: Open University Press.

Ajzen, I., \& Fishbein, M. (1977). Attitude-behavior relations: A theoretical analysis and review of empirical research. Psychological Bulletin, 84, 888-918.

Ajzen, I., \& Fishbein, M. (1980). Understanding attitudes and predicting social behavior, Englewood Cliffs, London: Prentice-Hall.

Alhabeeb, M. J. (2006). Consumer attitude and attribution. Allied Academies International Conference. Academy of Marketing Studies Proceedings, 11, 1-5.

Bagozzi, R. P., \& Phillips, L. W. (1982). Representing and testing organizational theories: A holistic construal. Administrative Science Quarterly, 27, 459-489.

Bagozzi, R. P., \& Yi, Y. (1988). On the evaluation of structural equation models. Journal of the Academy of Marketing Science, 16, 74-94.

Bandura, A. (1986). Social foundations of thought and action: A social cognitive theory, NJ: Prentice Hall.

Bamberg, S. (2003). How does environmental concern influence specific environmentally related behaviors? A new answer to an old question. Journal of Environmental Psychology, 23, 21-32. http://dx.doi.org/10.1016/S0272-4944(02)00078-6

Black, J. S., Stern, P. C., \& Elworth, J. T. (1985). Personal and contextual influences on household energy adaptations. Journal of Applied Psychology, 70, 3-21.

Bodur, H.O., Brinberg, D., \& Coupey, E. (2000). Belief, affect, and attitude: Alternative models of the determinants of attitude. Journal of Consumer Psychology, 9, 17-28.

Caruana, A., Money, A. H., \& Berthon, P. R. (2000). Service quality and satisfaction-the moderating role of value. European Journal of Marketing, 34, 1338-1353. http://dx.doi.org/10.1108/03090560010764432

Cohen, J., \& Cohen, P. (1983). Applied multiple regression, Hillsdale, NJ: Lawrence Erlbaum Associates.

Collins-Dodd, C., \& Lindley, T. (2003). Store brands and retail differentiation: the influence of store image and store brand attitude on store own brand perceptions. Journal of Retailing and Consumer Services, 10, 345-352.

Crabtree, S. (2000). Untangling the web. Retrieved from http://www.quirks.com/articles/a2000/20000708.aspx?searchID=627196893\&sort=5\&pg=1 
Cronbach, L. (1951). Coefficient alpha and the internal structure of tests. Psychometrika, 16, 297-334.

Crowne, D. P., \& Marlowe, D. (1960). The approval motive, New York: John Wiley.

Dabholkar, P. A., \& Bagozzi, R. P. (2002). An attitudinal model of technology-based self-service: Moderating effects of consumer traits and situational factors. Journal of Academy of Marketing Science, 30, 318-341.

Eagly, A. H., Mladinic, A., \& Otto, S. (1994). Cognitive and affective bases of attitudes toward social groups and social policies. Journal of Experimental Social Psychology, 30, 113-137.

Evans, R. J., \& Mathur, A. (2005). The value of online surveys. Internet Research, 15, 195-219. http://dx.doi.org/10.1108/10662240510590360

Feldman, J. M. (1981). Beyond attribution theory: Cognitive processes in performance $\begin{array}{lllll}\text { appraisal. Journal of Applied Psychology, 66, 127-148. } & \text {. }\end{array}$ http://dx.doi.org/10.1037/0021-9010.66.2.127

Foley, R. M., \& Pollard, C. M. (1998). Food Cent\$--implementing and evaluating a nutrition education project focusing on value for money. Australian and New Zealand Journal of Public Health, 22, 494-501. http://dx.doi.org/10.1111/j.1467-842X.1998.tb01420.x

Fransson, N., \& Gärling, T. (1999). Environmental concern: Conceptual definitions, measurement methods, and research findings. Journal of Environmental Psychology, 19, 369-382.

Gan, C., Wee, H. Y., Ozanne, L., \& Kao, T. H. (2008). Consumers' purchasing behavior towards green products in New Zealand. Innovative Marketing, 4, 93-102.

Göritz, A. S. (2004). The impact of material incentives on response quantity, response quality, sample composition, survey outcome, and cost in online access panels. International Journal of Market Research, 46, 327-345.

Harman, H. H. (1967). Modern Factor Analysis, Chicago: University of Chicago Press.

Hollnagel, E. (2002). Cognition as control: A pragmatic approach to the modelling of joint cognitive systems. Retrieved from http://www.ida.liu.se/ eriho/IEEE\%20ECOM.pd

Hu, L. T., \& Bentler, P. M. (1999). Cutoff criteria for fit indices in covariance structure analysis: Conventional criteria versus new alternatives. Structural Equation Modeling, 61, $1-55$.

James, D. (2000). The future of on-line research. Marketing News, 34, 1-1.

Kilbourne, W., \& Pickett, G. (2008). How materialism affects environmental beliefs, concern, and environmentally responsible behavior. Journal of Business Research, 61, 885-893.

Kushner, M. ., Sher, K. J., Wood, M. D. and Wood, P. K. (1994). Anxiety and drinking behavior: Moderating effects of tension-reduction alcohol outcome expectancies. Alcoholism: 
Clinical and Experimental Research, 18, 852-860.

Laroche, M., Tomiuk, M. A., Bergeron, J., \& Barbaro-Forleo, G. (2001). Targeting consumers who are willing to pay more for environmentally friendly products. Journal of Consumer Marketing, 18, 503-520. http://dx.doi.org/10.1108/EUM0000000006155

Laroche, M., Tomiuk, M. A., Bergeron, J., \& Barbaro-Forleo, G. (2002). Cultural Differences in environmental knowledge, attitudes, and Behaviors of Canadian Consumers. Canadian Journal of Administrative Sciences/Revue Canadienne des Sciences de l'Administration, 19, 267-282.

Lings, I. N. and Greenley, G. E. (2005). Measuring internal market orientation. Journal of Service Research, 7, 290-305.

Little, B. (2010). Criteria for value-for-money e-learning solutions. Training \& Management Development Methods, 24, 637-642.

McDevitt, P. K., \& Small, M. H. (2002). Proprietary market research: Are online panels appropriate? Marketing Intelligence \& Planning, 20, 285-296. http://dx.doi.org/10.1108/02634500210441530

Nunnally, J. C. (1978). Psychometric theory, New York: McGraw-Hill.

Oskamp, S., Harrington, M. J., Edwards, T. C., Sherwood, D. L., Okuda, S. M., \& Swanson, D. C. (1991). Factors influencing household recycling behavior. Environment and Behavior, 23, 494-519.

Panayotou, T. (1993). Green markets: The economics of sustainable development, San Francisco, Calif: ICS Press.

Paulhus, D. L. (1991). Measurement and control of response bias. In J. P. Robinson, P. R. Shaver, \& L. S. Wrightsman (eds.), Measurement of personality and social psychological attitudes (pp. 17-59). San Diego: Academic Press. http://dx.doi.org/10.1016/B978-0-12-590241-0.50006-X

Peattie, K., \& Crane, A. (2005). Green marketing: Legend, myth, farce or prophesy? Qualitative Market Research: An International Journal, 8, 357-370.

Podsakoff, P. M., MacKenzie, S. B., Lee, J. Y., \& Podsakoff, N. P. (2003). Common method biases in behavioral research: A critical review of the literature and recommended remedies. Journal of Applied Psychology, 88, 879-903.

Rambo, A. T. (2001). Report of findings of the project on environmental consciousness in Asia: Comparative studies of Japan, China (Hong Kong), Vietnam and Thailand. Paper presented at the The 8th International Workshop of the ECO ASIA Long-term Perspective Project, Tokyo.

Rex, E., \& Baumann, H. (2007). Beyond ecolabels: What green marketing can learn from conventional marketing. Journal of Cleaner Production, 15, 567-576. 
Richardson, P. S., Jain, A. K., \& Dick, A. S. (1996). Household store brand proneness: A $\begin{array}{lllll}\text { framework. Journal of } & \text { Retailing, } & 2, & 159-185 .\end{array}$ http://dx.doi.org/10.1016/S0022-4359(96)90012-3

Scherr, R. E., \& Hammer, D. (2009). Student behavior and epistemological framing: Examples from collaborative active-learning activities in physics. Cognition and Instruction, 27, 147-174.

Schultz, P. W. (2001). The structure of environmental concern: Concern for self, other people, and the biosphere. Journal of Environmental Psychology, 21, 327-339.

Strahan, R., \& Gerbasi, K. C. (1972). Short homogeneous versions of the Marlowe-Crowne social desirability scale. Journal of Clinical Psychology, 28, 191-193.

Sue, V. M., \& Ritter, L. A. (2007). Conducting online surveys, Thousand Oaks: SAGE Publications.

Swait, J., \& Sweeney, J. C. (2000). Perceived value and its impact on choice behavior in a retail setting. Journal of Retailing and Consumer Services, 7, 77-88.

Turel, O., Serenko, A., \& Bontis, N. (2007). User acceptance of wireless short messaging services: Deconstructing perceived value. Information \& Management, 44, 63-73.

Van Dam, Y. K., \& Apeldoorn, P. A. C. (1996). Sustainable Marketing. Journal of Macromarketing, 16, 45-56.

Waters, A. J., Burgess, A., Hughes, D. L., Jovanovic, J. L., Miller, E. K., Li, Y., \& Basen-Engquist, K. M. (2012). Outcome expectancies and expectancy accessibility in exercise behavior, Journal of Applied Social Psychology, 42, 414-439.

Williams, D. J. (2008), Ponder this II: Are we ready?, Bloomington: AuthorHouse.

Williams, D. M. P., Anderson, E. S. E., \& Winett, R. A. P. (2005). A review of the outcome expectancy construct in physical activity research. Annals of Behavioral Medicine, 29, 70-79.

Zikmund, W. G., \& Babin, B. J. (2007). Essentials of marketing research, Ohio: South-Western.

\section{Appendix}

Appendix 1. Summary of Construct Measures for All Three Studies

Environmental concern

1. I am very concerned about the environment.

2. Humans are severely abusing the environment.

3. I would be willing to reduce my consumption to help protect the environment.

4. Major political change is necessary to protect the natural environment.

5. Major social changes are necessary to protect the natural environment.

6. Anti-pollution laws should be enforced more strongly. 


\section{Macrothink}

Outcome expectancy

1. Pollution will be reduced.

2. Extinctions will be reduced.

3. Agricultural chemicals in the environment will be reduced.

4. Important resources will last longer.

5. Global warming will be less of a problem.

6. Ozone depletion will be less of a problem.

Perceived value for money

1. Public transport/organic vegetables/free-range eggs are good value for money.

Attitude

1. I will find that consuming public transport/organic vegetables/free-range eggs is bad-good.

2. I will find that consuming public transport/organic vegetables/free-range eggs is unpleasant-pleasant.

3. I will find that consuming public transport/organic vegetables/free-range eggs is worthless-valuable.

\section{Copyright Disclaimer}

Copyright for this article is retained by the author(s), with first publication rights granted to the journal.

This is an open-access article distributed under the terms and conditions of the Creative Commons Attribution license (http://creativecommons.org/licenses/by/3.0/). 